\title{
Short communication: Viable Mycobacterium avium subspecies paratuberculosis in retail artisanal Coalho cheese from Northeastern Brazil
}

\author{
A. C. S. Faria, ${ }^{*}$ D. G. G. Schwarz,† I. A. Carvalho,† B. B. Rocha,† K. N. De Carvalho Castro,‡ M. R. Silva,§ \\ and M. A. S. Moreirat ${ }^{1}$ \\ *Faculdade de Ciências Biológicas e da Saúde (FACISA/UNIVIÇOSA), Av. Maria de Paula Santana, 3815, Silvestre, CEP 36570-000, Viçosa, \\ Minas Gerais, Brazil \\ †Departamento de Medicina Veterinária, Universidade Federal de Viçosa (UFV), Av. P. H. Rolfs, s/n, Campus Universitário, CEP 36570-900, \\ Viçosa, Minas Gerais, Brazil \\ †Empresa Brasileira de Pesquisa Agropecuária do Meio Norte/Uep Parnaíba (EMBRAPA),Br 343, km 35, Cep 64200-970, Parnaíba, Piauí, Brazil \\ §Empresa Brasileira de Pesquisa Agropecuária Gado de Leite (EMBRAPA), Rua Eugênio do Nascimento, 610, CEP 36038-330, Juíz de Fora, \\ MG, Brazil
}

\section{ABSTRACT}

Mycobacterium avium ssp. paratuberculosis (MAP) is the etiologic agent of paratuberculosis and it potentially plays a role in Crohn's disease. In humans, the main route of transmission of MAP might be the intake of contaminated milk and dairy products. Considering that MAP has already been detected in many types of cheese in different counties, and that Coalho cheese is an important dairy product in northeastern Brazil, the aim of this study was to report the first detection of MAP in retail Coalho cheese in Brazil by PCR and culture. Of 30 retail Coalho cheese samples, 3 (10\%) amplified fragments of a similar size to that expected (626 bp) were obtained and viable MAP was recovered by culture from $1(3.3 \%)$ sample. The DNA from the positive culture sample was sequenced and showed $99 \%$ identity with the insertion sequence IS 900 deposited in GenBank. It was possible to identify the presence of MAP-specific DNA in the analyzed samples for the first time in Brazil, and to recover viable cells from retail Coalho cheese.

Key words: paratuberculosis, cheese, viable, culture

\section{Short Communication}

Mycobacterium avium ssp. paratuberculosis (MAP) is the etiological agent of paratuberculosis that affects all ruminant species worldwide (Chiodini et al., 1984), and the spread of MAP occurs through feces, semen, and milk (Ayele et al., 2004; Slana et al., 2008). In Brazil, the presence of MAP DNA and the viability of MAP in raw and retail pasteurized milk (Carvalho et al., 2009, 2012) has been proven, suggesting that live

Received December 15, 2013.

Accepted March 20, 2014.

${ }^{1}$ Corresponding author: masm@ufv.br organisms might be transmitted to humans by ingestion of contaminated products. Artisanal Coalho cheese is a popular dairy product widely consumed in the northeastern region of Brazil, being produced with raw or pasteurized milk, added to rennet, and subjected to cooking. According to Brazilian standards, Coalho cheese is categorized as a semi-hard cheese, presenting medium to high moisture, and a solids content ranging from 35 to $60 \%$ (Brasil, 2001). Under Brazilian legislation, Coalho cheese is produced following milk coagulation using rennet or another suitable coagulating enzyme and is sometimes supplemented with specific lactic acid bacteria (Brasil, 2001). In terms of sensory characteristics, the cheese has a slightly salty and sour taste, and it is widely used as a "roast cheese" because of its heat resistance and resistance to melting. The deficient sanitary management of dairy herds, as well as inappropriate care in cheese processing, implies an increasing risk of contamination by many microorganisms that depreciates the product and endangers human health.

Considering the implications to public health and the quality of Brazilian artisanal cheese, this study aimed to evaluate the presence of MAP in retail Coalho cheese in the region of Parnaíba, Piauí State, in northeastern Brazil. From November 2011 to January 2012, 30 samples of artisanal Coalho cheese were randomly collected from formal (bakery, small market, and supermarket) and informal (street stall) traders in Parnaíba city, Piauí State. The samples were stored at $-25^{\circ} \mathrm{C}$ until analysis at the Bacterial Disease Laboratory of the Federal University of Viçosa (Minas Gerais, Brazil). The outside of each sample bag was decontaminated with $70 \%$ ethanol and exposed to room decontamination with UV radiation for 30 min. Each sample package was then aseptically opened and $30 \mathrm{~g}$ was weighed and transferred to a new sterile Whirl-Pak bag (Nasco, Fort Atkinson, WI) for culture and DNA extraction. A 1\% 
$\mathrm{NaCl}$ solution was preheated at $37^{\circ} \mathrm{C}$ for $30 \mathrm{~min}$, and $125 \mathrm{~mL}$ was added to each bag, which were homogenized in a stomacher blender (Kleinfeld Labortechnik, Gehrden, Germany) for $2 \mathrm{~min}$ at $260 \mathrm{rpm}$. The homogenate was then incubated in a water bath at $37^{\circ} \mathrm{C}$ for $30 \mathrm{~min}$, and $30 \mathrm{~mL}$ of the resultant suspension was transferred to a sterile falcon tube for DNA extraction. Another $30 \mathrm{~mL}$ of the same suspension was transferred to another sterile falcon tube for culture with $0.75 \%$ hexadecyl pyridinium chloride (HPC; Sigma Chemical Co., St. Louis, MO).

After transfer of $30 \mathrm{~mL}$ of the homogenate to a 50$\mathrm{mL}$ falcon tube for DNA extraction, the solution was centrifuged at 4,200 $\times g$ for $15 \mathrm{~min}$ for the PCR assay, and the pellet was resuspended in $30 \mathrm{~mL}$ of $1 \% \mathrm{NaCl}$ solution and centrifuged at $4,200 \times g$ for $15 \mathrm{~min}$. The pellet was washed in $1 \mathrm{~mL}$ of PBS and the supernatant was transferred to a $1.5-\mathrm{mL}$ microtube and centrifuged at $14,100 \times g$ for $10 \mathrm{~min}$. Extraction of bacterial genomic DNA from cheese samples was performed using a Wizard Genomic DNA Purification Kit (Promega, Madison, WI), according to the manufacturer's instructions. The DNA was eluted in a final volume of 30 $\mu \mathrm{L}$ of MilliQ water (Millipore, Billerica, MA), and its concentration was determined using a NanoDrop Lite spectrophotometer (Thermo Scientific, Waltham, MA). For PCR reactions, the PCR kit GoTaq Green Master Mix (Promega) was used according to the manufacturer's instructions. Reactions were performed using the BN1 (5'-GTT ATT AAC GAC GCC CAG C-3') and BN2 (5'-ACG ATG CTG TGT TGG GCG TTA G-3') primers that amplify a 626 -bp fragment, based on the insertion sequence IS900, according to Sivakumar et al. (2005). Briefly, $12.5 \mu \mathrm{L}$ of mix, $1 \mu \mathrm{L}$ of each oligonucleotide, $6.5 \mu \mathrm{L}$ of MilliQ water, and $4 \mu \mathrm{L}$ of extracted DNA at a concentration of $200 \mathrm{ng} / \mu \mathrm{L}$ were used in a total reaction volume of $25 \mu \mathrm{L}$. Amplifications were carried out in a thermocycler (MaxyGene II Thermal Cycler, Corning Inc., Corning, NY) using an initial denaturation at $94^{\circ} \mathrm{C}$ for $4 \mathrm{~min}$, followed by 30 cycles of denaturation at $94^{\circ} \mathrm{C}$ for $1 \mathrm{~min}$, annealing at $60^{\circ} \mathrm{C}$ for $1 \mathrm{~min}$, and extension at $72^{\circ} \mathrm{C}$ for $1 \mathrm{~min}$, with a final extension at $72^{\circ} \mathrm{C}$ for $4 \mathrm{~min}$. Amplicons were analyzed by gel electrophoresis in 1\% (wt/vol) agarose gels (Invitrogen, Washington, DC) in 0.5 tris-borate-EDTA buffer stained with $1 \mu \mathrm{L}$ of GelRed (diluted 1:500; Biotium Inc., Hayward, CA) using UV radiation in an Eagle Eye II transilluminator (Stratagene, La Jolla, CA). The K-10 strain of MAP was used as the positive control, and ultrapure water was used as a negative control. A 100-bp DNA ladder (Promega) was used as a molecular weight standard.

A further $30 \mathrm{~mL}$ of the homogenate was transferred to a $50-\mathrm{mL}$ sterile falcon tube for culture and centri- fuged at $2,500 \times g$ for $15 \mathrm{~min}$. The supernatant was discarded and the pellet resuspended in $10 \mathrm{~mL}$ of $0.75 \%$ HPC in a dark room at room temperature for $5 \mathrm{~h}$, as previously described (Ikonomopoulos et al., 2005). Subsequently, samples were centrifuged at $2,500 \times g$ for $15 \mathrm{~min}$ and the supernatant was discarded. Finally, the remaining pellet was resuspended and washed with 1 $\mathrm{mL}$ of PBS, $\mathrm{pH} 7.2$, and a $250-\mu \mathrm{L}$ aliquot of the suspension was inoculated onto 2 Herrold's egg yolk medium (HEYM) slopes with or without $2 \mu \mathrm{L} / \mathrm{mL}$ of mycobactin $J$. After growth, the colonies were confirmed by IS 900 PCR and the amplified fragments were extracted and purified from agarose gels using the Wizard SV Gel kit and PCR Clean-Up System (Promega), according to the manufacturer's instructions. Both strands were sequenced in triplicate and the sequences obtained were aligned, edited, and compared with other sequences deposited in GenBank using BLAST (Basic Local Alignment Search Tool) software (http://blast.ncbi.nlm.nih. gov/Blast.cgi), available from the National Center for Biotechnology Information. Isolates grown in HEYM were collected, heat-fixed onto slides, and stained with the Ziehl-Neelsen (ZN) kit (Laborclin, Pinhais, Brazil) according to the manufacturer's instructions. Samples were then checked by optical microscopy for the presence of acid-fast bacilli.

Following PCR, MAP-specific DNA was detected in $10 \%(3 / 30)$ of Coalho cheese samples. Although PCR techniques sensitively detect the presence of the microorganism at certain points in cheese production, they do not distinguish living cells from dead cells. The detection of MAP has been shown in cheese produced by raw milk (Spahr and Schafroth, 2001; Stephan et al., 2007) as well as pasteurized milk (Sung and Collins, 2000; Donaghy et al., 2004; Clark et al., 2006) and it was shown that cheese ripening significantly decreases the viability of MAP. However, the efficiency of maturation is related to the degree of contamination of the raw milk used and to the efficiency of pasteurization. In general, using pasteurized milk and a 60-d curing period in cheese manufacture decreases the amount of initial MAP (Sung and Collins, 2000). In relation specifically to the Brazilian artisanal Coalho cheese, information is available regarding the presence and resistance of microorganisms in products produced from raw or pasteurized milk. However, the antimicrobial activity of the water-soluble peptide extracts, due to the proteolytic activity of the cheese process, recently showed that artisanal Coalho cheese can be considered a "functional food." Antimicrobial activity was found against Enterococcus faecalis, Bacillus subtilis, Escherichia coli, and Pseudomonas aeruginosa (Silva et al., 2012), but was not evaluated against Mycobacterium spp. The MAP viability in this type of cheese is likely 
related to a combination of factors inherent in the manufacturing process.

Some studies have investigated the viability of MAP in artificially inoculated cheeses to verify the parameters of survival of MAP in Hispanic-style cheese, hard (Swiss Emmentaler), semihard (Swiss Tilsiter), and Cheddar cheese (Sung and Collins, 2000; Spahr and Schafroth, 2001; Donaghy et al., 2004). Subsequently, attempts were made to isolate MAP from viable commercial cheeses (Ikonomopoulos et al., 2005; Clark et al., 2006; Stephan et al., 2007; Botsaris et al., 2010), but only Ikonomopoulos et al. (2005) were able to cultivate MAP successfully in retail cheeses from Greece and the Czech Republic. However, few colonies were obtained and these were not grown in secondary culture. In the current study, small, rough, whitish colonies with defined edges, similar to those observed by Collins (2003), were observed in 3.3\% (1/30) of samples after 12 wk of cultivation in HEYM supplemented with mycobactin $J$. The isolates were stained using the ZN kit and showed the presence of acid-fast bacilli. Similarly, Ikonomopoulos et al. (2005) confirmed that $3.6 \%$ of cultures were positive for MAP; other authors have found inferior results to $M$. bovis in relation to the isolation of MAP, about $0.5 \%(1 / 200)$ and $0.49 \%$ $(1 / 203)$ for the detection of viable cells in cheeses from Mexico by Harris et al. (2007) and Kinde et al. (2007), respectively. Difficulty in isolating MAP from cheeses might also be related to the HPC treatment, which is required to control contaminating microbiota and might interfere with the recovery of bacteria (Sung and Collins, 2000). It has been shown that the decontamination process in cheeses results in a $60 \%$ reduction in colony-forming units compared with nondecontaminated samples (Spahr and Schafroth, 2001). However, Dundee et al. (2001) concluded that treatment of fluid milk with $0.75 \%$ HPC for $5 \mathrm{~h}$ at room temperature was the best treatment compared with other protocols, allowing recovery of $28.7 \%$ viable MAP cells and detection of MAP at 10 to $100 \mathrm{cfu}$.

In this study, DNA from positive cultures was sequenced and compared with sequences deposited in GenBank. One of the positive PCR samples revealed 99\% similarity with the MAP UFV-JJ strain insertion sequence IS900 (GenBank: HM015768.1). Because of the distance between the region of collection and sample processing (from the northeast to the southeast of Brazil), the cheese samples were frozen at $-25^{\circ} \mathrm{C}$; however, positive results for both PCR and culture were obtained. It is known that MAP can tolerate extreme conditions and it was recently shown that MAP can survive for approximately $18 \mathrm{mo}$ in bovine fecal samples frozen at -18 to $-70^{\circ} \mathrm{C}$. However, the decrease in cell viability cell from a moderate-to-low bacterial load or from a low-to-negative bacterial load was $13 \%$ per month (Raizman et al., 2011).

As MAP has fastidious growth, the conditions for its multiplication in cheese are probably not optimal; thus, recovery of viable cells depends on the initial bacterial load and the type of cheese processing. An experiment conducted with hard and semihard cheeses showed that the MAP load decreases when the ripening time is increased (Spahr and Schafroth, 2001). In addition to the features of fastidious bacteria, variations in temperature can compromise the viability of some cells. Due to the temperature variation within the samples, we suspected that the initial load of contamination was high, mainly based on the recovery of viable MAP. However, from the data presented, it was not possible to confirm where the contamination occurred - whether it was from the raw material (bovine milk) or through inadequate manipulation during the preparation of artisanal Coalho cheese.

Our study confirmed the presence of MAP-specific DNA and viable cells in artisanal Coalho cheese from Piauí State in northeastern Brazil and provided evidence that MAP might remain viable in retail cheeses. This study has important implications, because MAP can be a coadjuvant agent in Crohn's disease, with a potential risk to susceptible individuals when ingesting dairy products contaminated with viable MAP. This is the first report of viable MAP in cheese in Brazil.

\section{ACKNOWLEDGMENTS}

The authors acknowledge financial support from $\mathrm{CNPq}$ (Conselho Nacional de Desenvolvimento Científico e Tecnológico, Brasília, Brazil), FAPEMIG (Fundação de Amparo à Pesquisa de Minas Gerais, Belo Horizonte, Brazil), and CAPES (Coordenação de Aperfeiçoamento de Pessoal de Nível Superior, Brasília, Brazil).

\section{REFERENCES}

Ayele, W. Y., M. Bartos, P. Svastovaand, and I. Pavlik. 2004. Distribution of Mycobacterium avium ssp. paratuberculosis in organs of naturally infected bull-calves and breeding bulls. Vet. Microbiol. 103:209-217.

Botsaris, G., I. Slana, M. Liapi, C. Dodd, C. Economides, C. Rees, and I. Pavlik. 2010. Rapid detection methods for viable Mycobacterium avium subspecies paratuberculosis in milk and cheese. Int. J. Food Microbiol. 141:S87-90.

Brasil (Ministério da Agricultura, Pecuária e Abastecimento Secretaria de Defesa Agropecuária). 2001. Regulamento técnico de identidade e qualidade de queijo de coalho-Instrução Normativo No. 30, de 26 de junho de 2001. Anexo II:5-8.

Carvalho, I. A., P. A. Pietralonga, D. G. G. Schwarz, A. C. S. Faria, and M. A. S. Moreira. 2012. Short communication: Recovery of viable Mycobacterium avium subspecies paratuberculosis from retail pasteurized whole milk in Brazil. J. Dairy Sci. 95:6946-6948.

Carvalho, I. A., A. Silva Jr., V. E. Camposand, and M. A. Moreira. 2009. Short communication: Detection of Mycobacterium avium 
subspecies paratuberculosis by polymerase chain reaction in bovine milk in Brazil. J. Dairy Sci. 92:5408-5410.

Chiodini, R. J., H. J. Van Kruiningen, and R. S. Merkal. 1984. Ruminant paratuberculosis (Johne's disease): The current status and future prospects. Cornell Vet. 74:218-262.

Clark, D. L., Jr., J. L. Anderson, J. J. Koziczkowski, and J. L. Ellingson. 2006. Detection of Mycobacterium avium subspecies paratuberculosis genetic components in retail cheese curds purchased in Wisconsin and Minnesota by PCR. Mol. Cell. Probes 20:197-202.

Collins, M. T. 2003. Update on paratuberculosis: 1. Epidemiology of Johne's disease and the biology of Mycobacterium paratuberculosis. Ir. Vet. J. 56:565-574.

Donaghy, J. A., N. L. Totton, and M. T. Rowe. 2004. Persistence of Mycobacterium paratuberculosis during manufacture and ripening of Cheddar cheese. Appl. Environ. Microbiol. 70:4899-4905.

Dundee, L., I. R. Grant, H. J. Ball, and M. T. Rowe. 2001. Comparative evaluation of four decontamination protocols for the isolation of Mycobacterium avium ssp. paratuberculosis from milk. Lett. Appl. Microbiol. 33:173-177.

Harris, N. B., J. Payeur, D. Bravo, R. Osorio, T. Stuber, D. Farrell, D. Paulson, S. Treviso, A. Mikolon, A. Rodriguez-Lainz, S. CernekHoskins, R. Rast, M. Ginsberg, and H. Kinde. 2007. Recovery of Mycobacterium bovis from soft fresh cheese originating in Mexico. Appl. Environ. Microbiol. 73:1025-1028.

Ikonomopoulos, J., I. Pavlik, M. Bartos, P. Svastova, W. A. Ayele, P. Roubal, J. Lukas, N. Cookand, and M. Gazouli. 2005. Detection of Mycobacterium avium ssp. paratuberculosis in retail cheeses from Greece and the Czech Republic. Appl. Environ. Microbiol. 71:8934-8936.

Kinde, H., A. Mikolon, A. Rodriguez-Lainz, C. Adams, R. L. Walker, S. Cernek-Hoskins, S. Treviso, M. Ginsberg, R. Rast, and B. Har- ris. 2007. Recovery of Salmonella, Listeria monocytogenes, and Mycobacterium bovis from cheese entering the United States through a noncommercial land port of entry. J. Food Prot. 70:47-52.

Raizman, E. A., L. A. Espejo, and S. J. Wells. 2011. Long-term survival of Mycobacterium avium ssp. paratuberculosis in fecal samples obtained from naturally infected cows and stored at $-18^{\circ} \mathrm{C}$ and $-70^{\circ}$ C. Vet. Med. Int. 2011:341691.

Silva, R. A., M. S. F. Lima, J. B. M. Viana, V. S. Bezerra, M. C. B. Pimentel, A. L. F. Porto, M. T. H. Cavalcanti, and J. L. Lima Filho. 2012. Can artisanal "Coalho" cheese from Northeastern Brazil be used as a functional food? Food Chem. 135:1533-1538.

Sivakumar, P., B. N. Tripathi, and N. Singh. 2005. Detection of Mycobacterium avium $\mathrm{ssp}$. paratuberculosis in intestinal and lymph node tissues of water buffaloes (Bubalus bubalis) by PCR and bacterial culture. Vet.Microbiol. 108:263-270.

Slana, I., F. Paolicchi, B. Janstova, P. Navratilova, and I. Pavlik. 2008 Detection methods for Mycobacterium avium ssp. paratuberculosis in milk and milk products: A review. Vet. Med. 53:283-306.

Spahr, U., and K. Schafroth. 2001. Fate of Mycobacterium avium ssp. paratuberculosis in Swiss hard and semihard cheese manufactured from raw milk. Appl. Environ. Microbiol. 67:4199-4205.

Stephan, R., S. Schumacher, T. Tasara, and I. R. Grant. 2007. Prevalence of Mycobacterium avium subspecies paratuberculosis in Swiss raw milk cheeses collected at the retail level. J. Dairy Sci 90:3590-3595.

Sung, N., and M. T. Collins. 2000. Effect of three factors in cheese production ( $\mathrm{pH}$, salt and heat) on Mycobacterium avium ssp. paratuberculosis viability. Appl. Environ. Microbiol. 66:1334-1339. 